\title{
A free lung health check for the European Parliament: Healthy Lungs for Life
}

\author{
Marine Faure \\ Affiliation: European Respiratory Society, EU Affairs Brussels, Brussels, Belgium. \\ Correspondence: Marine Faure, European Respiratory Society, EU Affairs Brussels, Brussels, Belgium. \\ E-mail: Marine.Fauredersnet.org
}

0 @ERSpublications

ERS and ELF are committed to raising awareness on the importance of lung health among EU policy makers http://ow.ly/JV3nD

Marcel Proust, the celebrated early twentieth century French writer, suffered from severe bronchial asthma his entire life, eventually succumbing to pneumonia. In 1900, he wrote: "An attack of asthma of unbelievable violence and tenacity - such is the depressing balance sheet of my night, which it obliged me to spend on my feet in spite of the early hour at which I got up yesterday." In the twenty first century, 600000 Europeans continue to die prematurely from lung diseases [1]. Asthma, chronic obstructive respiratory disease (COPD), lung cancer, pulmonary hypertension and other respiratory diseases are, in combination, responsible for one in eight deaths in the 28 countries of the European Union [1]. When they do not result in death, they may harshly affect the life of the individuals or become a heavy economic burden for society. Hospital costs, treatments and loss of productivity, due to a patient's inability to work and premature death, are estimated at more than $€ 380$ billion [1].

Science has progressed since Marcel Proust's asthma and many respiratory diseases are now preventable or treatable. Yet, lung health is not always prioritised by individuals or policymakers and even where it is, it may be a case of too little too late [2].

In light of this, the European Respiratory Society (ERS) European Union (EU) Affairs office, together with the European Lung foundation (ELF) launched the Healthy Lungs for Life campaign at the European Parliament, which ran from January 19-21, 2015. The purpose of the campaign was to raise awareness of the importance of healthy lungs among European policymakers and the public, through various events, projects and promotional activities. In the context of the EU air quality package [3] that legislates for national emissions of pollutants, but is under the threat of modification, a particular emphasis was placed on the importance of clean air for our health.

The first two days included an exhibition providing fact sheets, booklets, a quiz on respiratory diseases and air pollution, and the opportunity for Members of the European Parliament (MEP) and European Parliament staff to undertake a free lung check. The Healthy Lungs for Life stand was equipped with four tests stations that were manned by a team of 20 spirometry testers. The event was an outstanding success with 524 people volunteering to get their lungs checked. These included over 40 MEPs from 18 different countries such as the UK, France, Germany and Italy. The latter being a key audience, which ERS advocacy activities are targeted towards, as they debate and vote on legislation that impacts on EU citizens' health. From this cohort, $40 \%$ of the 524 people tested were said to be current or former smokers, of which $10 \%$ had abnormal results and were advised to consult a doctor. These results show the usefulness of lung function tests to raise awareness on the importance of lung health.

Similarly, the quiz undertaken by the participants revealed some interesting results. Most of them frequently underestimated the number of people who die prematurely as a consequence of air pollution globally [4]. In addition, for the question "What is the percentage of people affected by air pollution?"

Received: Feb 092015 | Accepted: Feb 182015

Conflict of interest: Marine Faure is an employee of the European Respiratory Society

Copyright OERS 2015 
a large proportion of the participants answered $80 \%$ or $90 \%$, ignoring that $100 \%$ of the population is exposed to air and accordingly concerned by air pollution. The lack of knowledge on that matter shows that individuals are partially unaware of the dramatic impact air pollution has on their lungs. Public education is now, more than ever, necessary in order for citizens to find the best ways to protect themselves.

The third day was dedicated to a roundtable, which brought together ERS physicians and EU policymakers, as well as stakeholders having a particular interest in health. Prof. Elisabeth Bel, President of the ERS, drew attention to the main respiratory diseases risk factors and recalled that "prevention is one of the key parts to reduce the burden of lung disease". Prof. Bert Brunekreef, chair of the ERS Environment and Health Committee, pointed out the poor air quality EU citizens breathe every day and called on the EU to better enforce the air quality package. Prof. Peter Calverley, chair of the COPD Working Group, emphasised the future challenges we must meet with regards to COPD by "raising awareness, getting better data, developing effective early intervention strategies and support research into new treatment and management options". Dr Constantine Vardavas, ERS member of the Tobacco Control Committee (TCC), presented SmokeHaz (collaboration between ERS, The UK Centre for Tobacco and Alcohol Studies, and ELF [5]) and outlined the results of a TCC's report on second-hand smoke. The study reveals that $29 \%$ of all EU nonsmoking respondents reported being highly exposed to second-hand smoke, particularly in the bars $(n=25,3 \%)$. This shows the importance of adopting and enforcing comprehensive smoke-free legislation in all EU Member states. Dr Claudiu Ciprian Tănăsescu, speaking as the European Parliament host of the event, concluded by highlighting the unacceptable economic burden of air pollution and lack of prevention: "In 2010, the economic impact accounted for 15 billion from workdays lost and four billion in healthcare costs". The following reception was attended by relevant health stakeholders, such as Lanfranco Fanti, member of the Environment Commissioner's cabinet and Roberto Bertolini, Chief Scientist and World Health Organization representative to the European Union.

Throughout three-day event ERS, once again, has established itself as the leading organisation at promoting respiratory health among the Brussels sphere of European policymakers and stakeholders. A significant number of MEPs and various stakeholders showed great interest in having their lung functions examined, as well as having a look at the exhibition and attending the roundtable. As Healthy Lungs for Life is not a one-shot awareness raising action, the campaign will travel around Europe every year to inform EU citizens on how to keep their lungs healthy and prevent disease. The next stop will be in Amsterdam, as part of the ERS International Congress September 26-30, 2015. Here activities will take place both in the congress itself and within the city [6]. With events such as this and other campaigns ERS is hopefully consigning cases like Proust's to the history books.

FIGURE 1 MEP Jadwiga Wiśniewska taking a lung health check, as part of the Healthy Lungs for Life campaign at the European parliament, 19-21 January 2015.

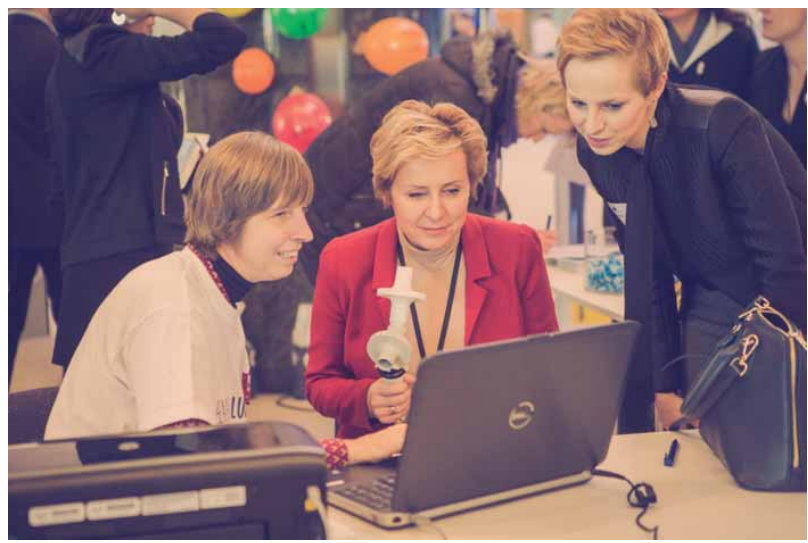

\section{References}

1 Gibson J, Loddenkemper R, Sibille Y, et al. The European Lung White Book: Respiratory Health and Disease in Europe. 2nd Ed. Sheffield, European Respiratory Society, 2013.

2 Decramer M, Sibille Y. European Respiratory Roadmap. Sheffield, European Respiratory, 2011.

3 European Commission. The Clean Air Policy Package. http://ec.europa.eu/environment/air/clean_air_policy.htm Date late accessed: February 3, 2015.

4 World Health Organization. Burden of disease from the joint effects of Household and Ambient Air Pollution for 2012. Geneva, World Health Organization, 2014. Available from: http://www.who.int/phe/health_topics/outdoorair/ databases/AP_jointeffect_BoD_results_March2014.pdf?ua=1

5 Euroeapen Lung Foundation. SmokeHaz: A Scientific Review of the Health Hazards of smoking. http://www. europeanlung.org/en/projects-and-research/projects/smokehaz/home Date late accessed: February 3, 2015.

6 European Respiratory Society European Lung Foundation. Healthy Lungs for Life. http://www.europeanlung.org/en/ projects-and-research/projects/healthy-lungs-for-life/home/ Date late accessed: February 3, 2015. 